\title{
Life-cycle management of educational programs and resources in a smart learning environment
}

\author{
Alexey Finogeev ${ }^{1 *}$ D, Alla Kravets ${ }^{3}$, Michael Deev $^{1}$, Alexandr Bershadsky ${ }^{1}$ and Leyla Gamidullaeva ${ }^{2}$
}

\author{
* Correspondence: \\ alexeyfinogeev@gmail.com \\ ${ }^{1}$ CAD-Department, Penza State \\ University, 40, Krasnay st., Penza, \\ Russia 440025 \\ Full list of author information is \\ available at the end of the article
}

\begin{abstract}
Lifecycle management questions of educational program and resources in the smart learning environment are considered to provide a convergent process of specialist's continuous training. The main results of the research are: (a) analysis of the training specialist's problems, (b) smart environment synthesis to support convergent education processes, (c) lifecycles formalization of the educational environment components, (d) synchronization of lifecycle models, (e) personalized learning paths synthesis, (f) support for the updating of educational resources according to the standards and employer's requirements. The article describes the results of the development of educational environment components. Functional lifecycle models and a cloud storage model for educational content with ubiquitous access support through the Web portal are proposed. The intellectual management system for the learning process in the information educational environment based on the component's lifecycle model is implemented. The intellectual platform includes content management system Alfresco, learning management system Moodle, training content presentation Web system, knowledge assessment system, learning activity management system, standards and employer's requirements analysis system. The system provides support for lifecycle stages of personalized educational programs, electronic educational resources, and specialist training levels.

Keywords: Smart learning environment, Convergent education, Educational program, Educational content, Lifecycle, Specialists training, Content management system, Learning management system, Lifecycle model synchronization, Training trajectory
\end{abstract}

\section{Background}

E-learning is an educational system that uses information and telecommunication technologies, although UNESCO specialists define it as learning through the Internet and multimedia technologies. In any case, the learning processes are provided by these technologies for working with electronic educational resources (Hamidi, 2011). Evolutionary development of wireless networks has led to the spread a ubiquitous access technologies (Horton, 2000). Such access defines a road map for the modernization of the learning processes in the direction of creating distributed personalized environments for the continuous training of specialists (Deev et al., 2014). Smart learning environment is designed to support the convergence of advanced learning

(c) The Author(s). 2018 Open Access This article is distributed under the terms of the Creative Commons Attribution 4.0 International License (http://creativecommons.org/licenses/by/4.0/), which permits unrestricted use, distribution, and reproduction in any medium, provided you give appropriate credit to the original author(s) and the source, provide a link to the Creative Commons license, and indicate if changes were made. 
technologies such as (a) e-learning (Cloete, 2001), (b) m-learning (Duncan-Howell and Lee, 2007), (d) cloud learning (Bhatia et al., 2012), (c) blended learning (Bersin, 2004) and (e) ubiquitous learning (Hwang, 2006). It provides an opportunity for adaptive intellectual management of the lifecycles of electronic educational resources, educational programs and specialist's training level.

Modern trends in education are (NMC Horizon Report, 2017):

a) application of mobile devices (laptops, smart phones, tablets, smart gadgets) and technologies for remote access to educational resources,

b) creation of Web resources and use of Web technologies for the publication of educational materials,

c) implementation of cloud learning technologies (Google Classroom, Moodle, Blackboard, "Mobile Electronic School”, etc.),

d) application of distance technologies for the interaction of teachers and students through Internet communication systems (e-mail, chat, blogs, forums, IP-phone) (Olofsson et al., 2011),

e) the creation of the social networks communities of teachers and students, as a tool for their interaction,

f) introduction of virtual and augmented reality technologies, 3D-printing for combining digital media with real objects and blended learning in the classroom and virtual reality,

g) application of gaming technology that combines the learning process with game elements,

h) interaction with employers at all training stages to adjust educational programs.

These trends require the creation of an intellectual environment for integrating educational resources and technologies, systems for supporting distance and open education, lifecycle management tools for environmental components. The smart learning environment assumes the integration of an educational content management system, a learning management system, a learning activity management system, the tools for intellectual analysis of the standard and employer requirements, systems for forecasting the needs of specialists in labor markets. The main components are already present on the market. In particular, a large number of educational management systems are proposed (Finogeev et al., 2015). Systems are used to develop, integrate, disseminate and update educational, methodological, regulatory and didactic materials with the possibility of ubiquitous and mobile access. Most modern learning systems use electronic resources with content and metadata.

The problems of modern education are:

1. Absence of adequate models of lifecycles of educational programs, resources and skill levels of trainees that allow automating the processes of synthesis and configuration of personal learning environments (Kravets et al., 2016).

2. The inconsistency of state educational programs and educational content with modern requirements of employers and absence the synchronization and actualization mechanisms. 
3. Absence of the intellectual analysis tools for employers requirements and comparison with competences in state educational standards.

The goal of creating a convergent educational platform is synchronization of electronic educational resources, programs, standards and employers requirements. The result is the interaction of the environment's components and student's qualification level and the synthesis of personalized learning space (Personal Learning Environment, 2008; Severance and Whyte, 2008). The objectives of lifecycles management of a environment's components are:

1. Creation a lifecycle's models for electronic educational resources, educational programs and training levels,

2. Development of a method for synchronizing educational programs, resources, training levels and employers requirements,

3. Development and implementation a lifecycle management tools,

4. Development a monitoring tools for monitoring and controlling the synchronization process,

5. Development of a methodology for assessing the effectiveness of the synchronization process,

6. Integration of tools and components into the smart learning environment.

\section{Convergent education concept}

The term convergence was introduced in 2002 by Bainbridge and Roco ( $\mathrm{M}$ Roco and W Bainbridge, 2004, W Bainbridge and M Roco,2005) to determine the convergence process of nano-, bio-, information, cognitive and social technologies. The result of convergence is the creation of a multi-structural environment for human life support (Finogeev et al., 2017). The convergence process is associated with the evolutionary development of information and telecommunication technologies, the emergence of innovations in the interdisciplinary field of knowledge. Information and technological convergence means the technologies interpenetration and the boundaries blurring between them, when results and innovations appear at the various science and technology fields (Chul and Gunno, 2016).

The convergence of educational, social, cognitive and information technologies determines the concept of convergent education (Canton, 2004). It complements the well-known approach of holistic education, based on the application of the systemic principle of integrity [Miller, 2000]. Holistic education is a philosophy of education based on the premise that each person finds identity, meaning, and purpose in life through connections to the community, to the natural world and to humanitarian values. The basic property of a holistic approach is emergence, when new qualities of the system appear as the result of joining parts. Thus, in the process of mastering a multitude of different disciplines,e the student has the necessary qualifications as a new emergent quality. Convergent approach, in our opinion, is not a philosophy, but a methodology for combining various technologies and information storages in an interdisciplinary educational environment for the synthesis of a new tool for obtaining knowledge. The basis of a convergent approach is not the integration processes, as in the case of a holistic perspective, but the synergistic interaction of educational, cognitive, social, information, telecommunication and neurobiological technologies. 
The ultimate goal is the consciousness immersion into the educational information cloud through the neuro interface. The development of augmented and virtual reality technology allows to obtain educational information through the visual interface, which has the largest bandwidth. In the future the trend in the creation of the neuro-interface «brain-educational space» will become a driver for the transition to virtual learning environments. Convergent approach to the learning environment synthesis determines the convergence of educational programs and standards for different specialties, as well as the convergence of educational resources, systems and teaching methods (Schatsky et al., 2015).

The main types of education convergence should be considered:

1. Technological convergence of a teaching technologies, learning programs and resources lifecycles;

2. Methodological convergence of a learning programs and electronic educational resources of different disciplines;

3. Professional convergence of a various specialists qualifications, competences from educational standards and employer's requirements;

4. Organizational convergence of a content management and a learning management platforms in a unified information and educational environment;

5. Convergence of creative and cognitive technologies in a specialists training for professional activities in various areas.

The result of convergence is the synthesis of the smart learning environment. The lifelong learning process includes: (a) study, (b) research, (c) creativity, (d) analysis, (e) discussion, (f) publication activity and (g) project activities. The convergent model of the SME describes the learning technologies integration on a single platform (Chan et al., 2001) with content management and presentation systems, knowledge assessment, learning process management, accounting standards and employers requirements. The model describes:

1. A convergence of a lifecycle models for educational programs, content and specialist training levels;

2. A convergence process of educational technologies.

3. An integration process of a learning management and learning activity management systems on a cloud educational content and ubiquitous access.

4. An adaptation process of a control and administration mechanisms of educational components.

The new education model determines the convergence of the educational standards competences with employer's requirements. This process is carried out at all lifecycle's stages of the specialist's qualifications, including at the training stage in colleges and universities and at the retraining and advanced training stages. Such moments as position change, labor functions change, scientific and technological progress require the acquired competences improvement or the new competences acquisition that lie beyond the specialist's qualifications limits. The modern specialist must constantly engage in self-education, so that his competencies meet employer's requirements. 
However, self-education is often not enough to gain new competencies. Educational programs for retraining should be coordinated with the specialist's training level and new employer's requirements. Input and control actions, output information and training mechanisms are shown on the specialist's training diagram, shown in Fig. 1.

\section{Management of the lifecycles synchronization}

The lifecycle's concept of a system determines a successive change in its evolution stages. The educational program, like the system, also goes through the lifecycle, shown in Fig. 2. The training programs content for specialists of different directions has recently coincided on a number of points. Specialists require similar competencies in the work, especially with respect to information technology.

The first stage of the program's lifecycle is an analysis of the standards and employers requirements. Planning is the next step, which collects information about educational resources for the learning process. The next stage is the development of a program and a tool for assessing it for compliance with the standards and employers requirements. The program's implementation involves the training technologies selection and the educational process planning. The learning process is performed using selected or synthesized educational resources. The program's implementation is completed by evaluating the obtained competences (Van Gog et al., 2010).

The process of program convergence is related to the lifecycle of educational content. The lifecycle of the electronic educational resource includes the creation stage, its use, modernization and moral aging. The process of a resource's creating begins with the analysis of external requirements (required formats and technologies, information materials, normative documents), the requirements of the specific training program and the conditions for its implementation (training technologies, content requirements). Based on the analysis, the resource's design is carried out, taking into account the requirements for it from the program for which it is developed. Further steps are implementation (taking into account the refined structure and the program material's content), component integration, version control, verification and publication. The

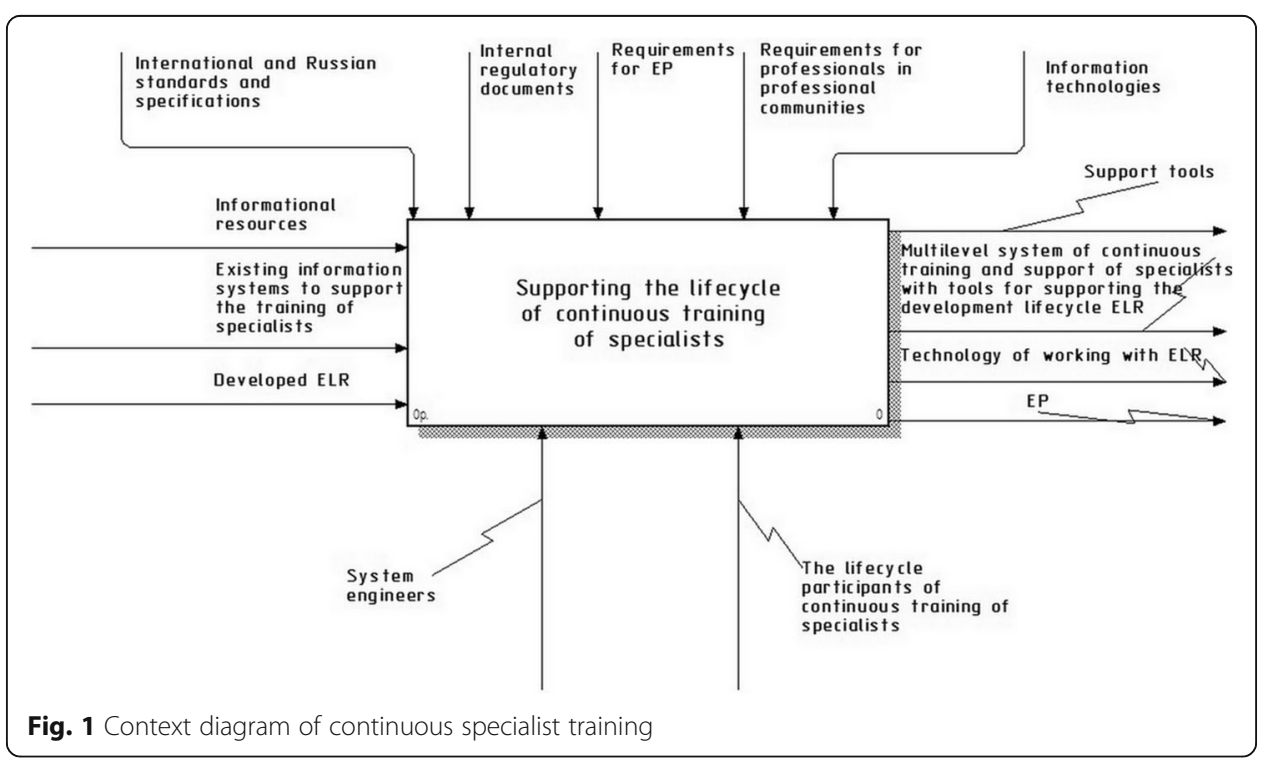




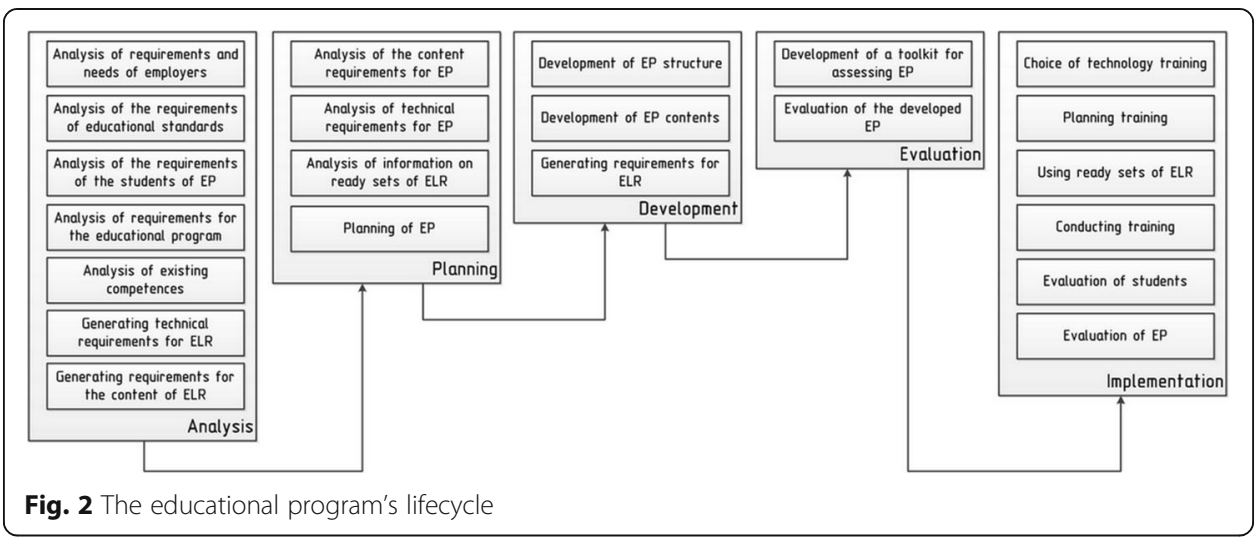

content is used in the training program's implementation, as well as in the specialist's self-education in the framework of convergent education.

Convergent process is the synchronization and harmonization of educational standards, training programs, educational content and specialist's skill levels in obtaining competences from various knowledge fields within the framework of the convergent education model, shown in Fig. 3.

A graph model has been developed to formalize the process of lifecycle's synchronization, shown in Fig. 4.

The model represents the oriented graph $\mathrm{M}=\{\mathrm{F}, \mathrm{S}, \mathrm{X})\}$, where $\mathrm{F}$ is the synchronization process, $\mathrm{S}$ is the contiguity matrix, $\mathrm{X}$ is the incidence matrix. The vertices of the three main subgraphs in the model denote the life cycle's stages of the

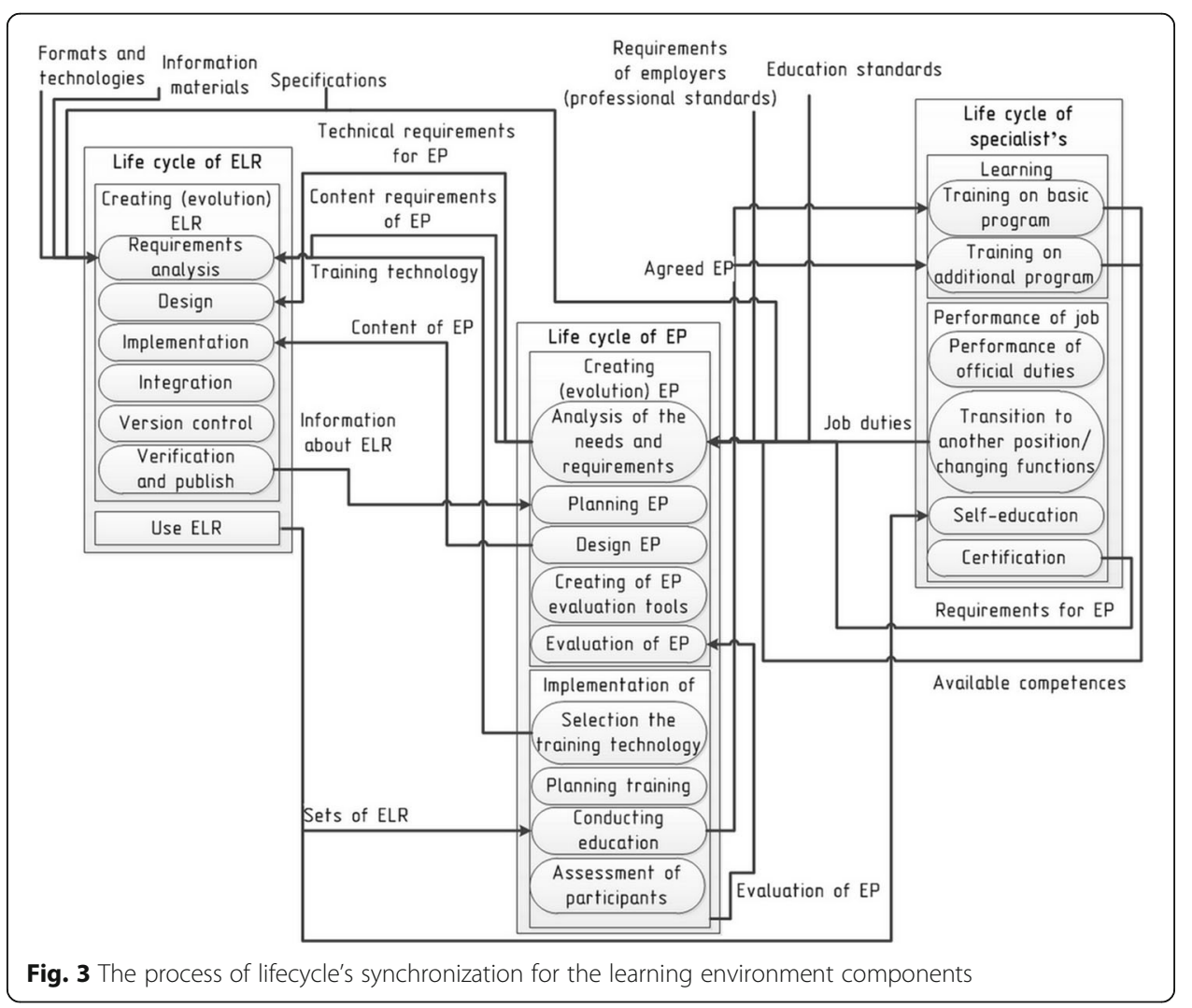




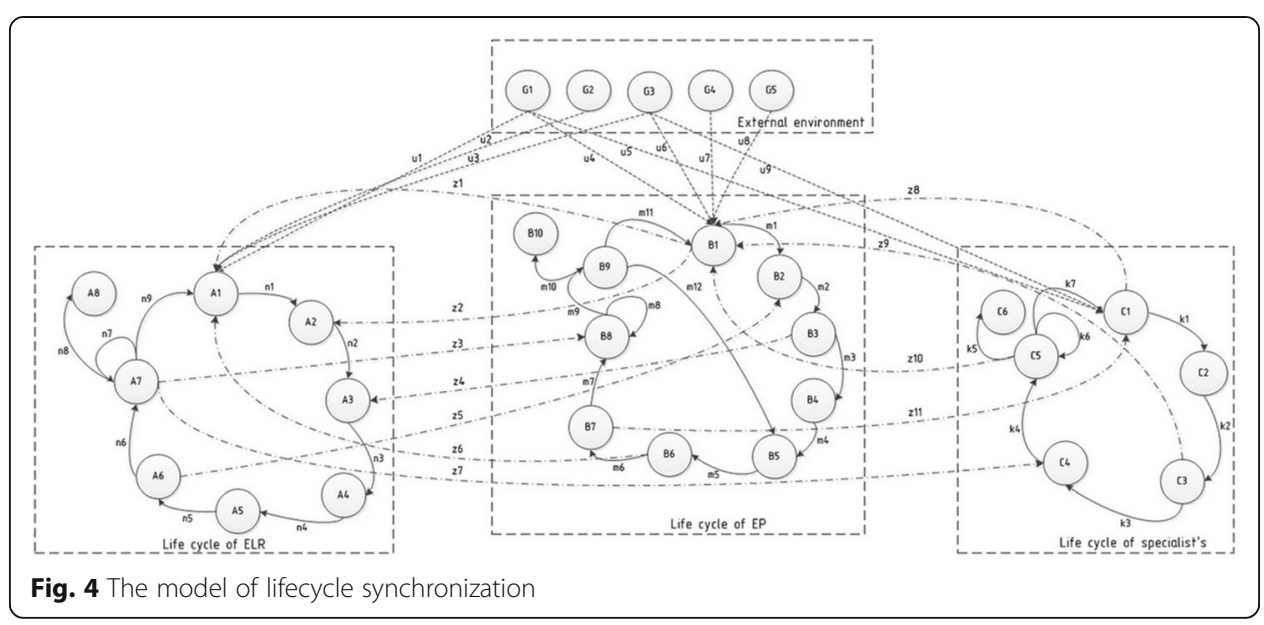

main environment components. Vertices A1-A8 determine the lifecycle stages of electronic educational content: requirements analysis, design, implementation, integration, version control, verification and publication, content use, decommissioning. These stages can be divided into subsets of vertices. For example, the requirements analysis phase involves methodological analysis, analysis of technical requirements, content analysis. The design stage includes actions for structural content analysis, its design, definition of presentation formats for users, etc. The implementation phase includes presentation in the required format, saving. The verification stage contains the stages of checking for compliance with standards, employers' requirements.

Vertexes B1-B10 designate the lifecycle's stages of the educational program: the requirements analysis, the educational program planning, the development, the assessment tools creation, evaluation, the teaching technology choice, the learning process organization, the training, the participant's evaluation, the program decommissioning. Vertices C1-C6 designate the lifecycle stages of the trainee's qualifications level: training, performing job duties, switching to another position, self-education, attestation, graduation. The fourth sub-graph defines the components G1-G5 of the external environment in relation to the intellectual educational space, namely: teaching technologies, information materials, regulatory documents, employers' requirements, standards' requirements.

To test the synchronization model's adequacy and evaluate the convergent educational process, integrated indicators of the training specialist's quality were developed (Hirner and Kochtanek, 2012).

\section{The smart learning environment's architecture}

The main components are: (a) the learning management system Moodle (Cooch, 2010), (b) the content management system Alfresco (Alfresco website, 2014), (c) the learning activity management system (LAMS Internationalization website, 2012), (d) the module for employers' requirements collecting and intellectual analysis.

Integration of these components allows implementing the adaptive lifecycle management of training components and educational technologies. In the educational space, personalized student's environments are synthesized, united in clusters according to the preparation level, socionic types, psychological portraits and other characteristics (Deev 
et al., 2015). The introduction of a personalized learning process based on the lifecycle models synchronization for the environment components ensures the learning process monitoring and the educational trajectories changing taking into account the changing standards and employer's requirements. The mechanisms help to analyze the destabilizing factors, leading to the risks of obtaining a low-quality and obsolete education.

The educational management system is an instrumental tool for creating and modifying educational programs. The learning activity management system has the functionality to manage learning activities and is used to develop, upgrade and distribute online training materials with the provision of shared access. The learning management system Moodle is suitable for managing the specialist's training in the smart learning environment in most cases. It represents the distance learning platform. The structure of the system includes categories and courses where educational content is located. Categories combine courses related to similar topics. In each course, you can use various elements (questionnaires, lectures, polls, forums, tests, hyperlinks, books, files, etc.) as tools to support the learning process. The system Moodle provides a large list of functions and representational state transfer queries and uses the access keys for authorization. To access requests in the system, you must create a web service with only authorized user's access to it, assign functions related to checking and generating categories and courses, select users and create authorization keys for them.

Currently, there are a lot of different content management system for creating, editing and managing Web content. Content management system works with multimedia data: documents, video and audio material, images and photos. The main purpose of such systems is the storage and Web publishing of information materials. The information educational space is created on the system Alfresco, which implements the basic functionality of supporting the component's lifecycles. To support the life cycle synchronization process, the environment's components developed new modules in the form of web scripts and dashlets. The Alfresco web script is a request service that is linked to a specific universal resource identifier.

For educational resources and data exchange between the environment's components, the following technologies and formats are used:

1. Requirements for educational programs and resources are exported in XML format (eXtensible Markup Language).

2. Representational state transfer (REST) and Web distributed authoring and yersioning (WebDAV) protocols are used to access educational resource kits.

3. Data on the use of educational resources are transmitted through Asynchronous Javascript and XML requests in the text-based JavaScript Object Notation data exchange format.

The methodology of work in a learning environment includes the following main stages:

1. Search, analysis and selection of standards and employers' requirements for educational programs and electronic educational resources.

2. Export requirements to the Alfresco system and to the Moodle system. 
3. Synthesis of electronic educational resources in the Alfresco, taking into account the requirements and information about the previously created content in the Moodle system.

4. Synthesis of a personalized training program according to the specialist training level, taking into account the standards and employer's requirements (Harmelen, 2008).

5. Selection and filling of a personalized training program for a specialist with a certain level of qualification with electronic educational resources.

6. Training specialists using the toolkit environment from Moodle system.

7. Competences evaluation in accordance with the standards and employer's requirements and making decisions on training completion or referral for retraining with correction of the personalized training trajectory.

Many scripts have been developed for support the training specialist's technology. It's can be divided into 2 main types: data repository scripts and presentation scripts. Data processing scripts are designed for reading, changing and accessing educational content through the application programming interface for JavaScript. Presentation scripts are required to provide a Web interface. Sample scripts:

1. Viewfiles webscript provides data collection for building a cloud storage tree with educational content, defines documents and folders, returns a response to requests in the JSON format,.

2. Repository-operation webscript performs file operations on documents and folders in accordance with user rights (copying, moving, renaming, creating directories, deleting), returns the status of the execution results.

3. My-favorite webscript adds documents and folders to "favorites", deletes them, returns the execution status.

4. Get-path webscript gets information about the directory location, returns the path to the object.

5. Get-xml webscript gets the file structure and writes it to an XML file with nested elements, returns a link to the generated file.

JavaScript dashlet controls the menu buttons pressing, events, is responsible for displaying the data, creates and processes requests. Its main functions include: directory tree display, electronic educational resource viewing, resource metadata changing, resource saving, folders XML exporting, directories creating, viewing, copying, moving, deleting, adding a resource to your favorites.

In the process of synthesizing educational programs and training, a large number of educational resources are used in different subjects, areas and complexity levels. To solve the problem, a cloud storage with a set of electronic educational resources and various information and regulatory materials are developed. The model of the educational content warehouse is represented, shown Fig. 5. The model contains the main storage entities with the specified attributes and relationships between them.

The diagram shows the basic entities, namely educational programs, objects, version archives, object types, availability status, object relationships. The versions of 


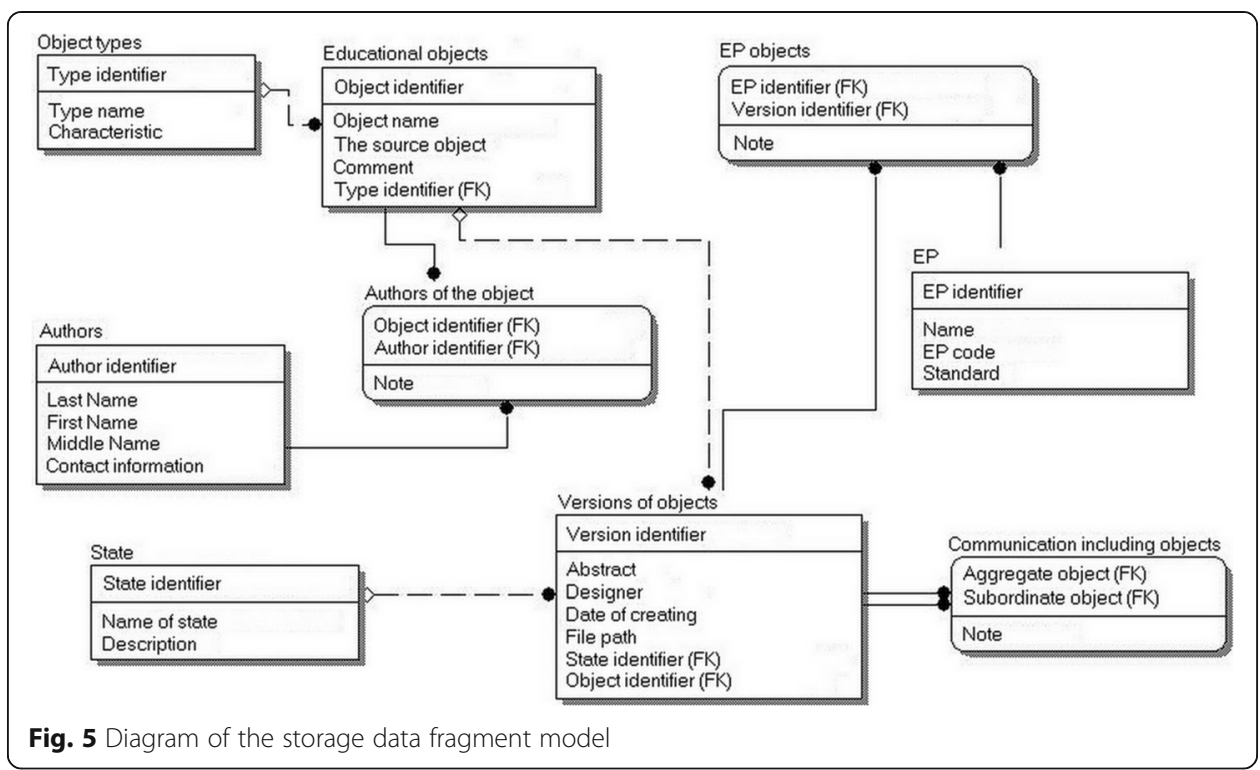

educational content contain comments that indicate changes in relation to previous versions. Interconnections are established between the initial information and regulatory materials and ready-made versions of electronic educational resources. Many versions of educational content allow you to monitor the stages of its lifecycle and use different versions for training in different disciplines and directions within the framework of the convergent education model. Since the development of educational content is often performed by author's team, it is also necessary to store data on the modernization and refinement of previously created elements of educational content. Content authors can change at the lifecycle stages of an electronic resource. Therefore, the convergence model defines one more lifecycle feature of educational content. The parts of content developed for one educational program can be repeated many times in electronic educational resources intended for other programs. At the same time, convergence of training programs leads to the fact that the number of repeating parts should strive for maximum. Therefore, content's fragments in one direction completely or with adjustments are included in electronic educational resources in other directions. An example is the animated videos that are used to demonstrate the work of the models ISO/OSI and TCP/IP. Rollers are used in any resources in the areas related to computer networks, administration of information systems, work on the Internet, etc.

The environment's architecture with intellectual mechanisms for training managing is built as like an open information system shown in Fig. 6.

Intellectual modules include:

1. A modules of search, intellectual analysis and clustering of educational standards and employers requirements.

2. A module for automated synthesis of personalized or group training trajectories in accordance with the identified clusters of standards and employers.

3. A module for predicting the training results on personalized trajectories based on neural networks with the deep learning mechanism. 


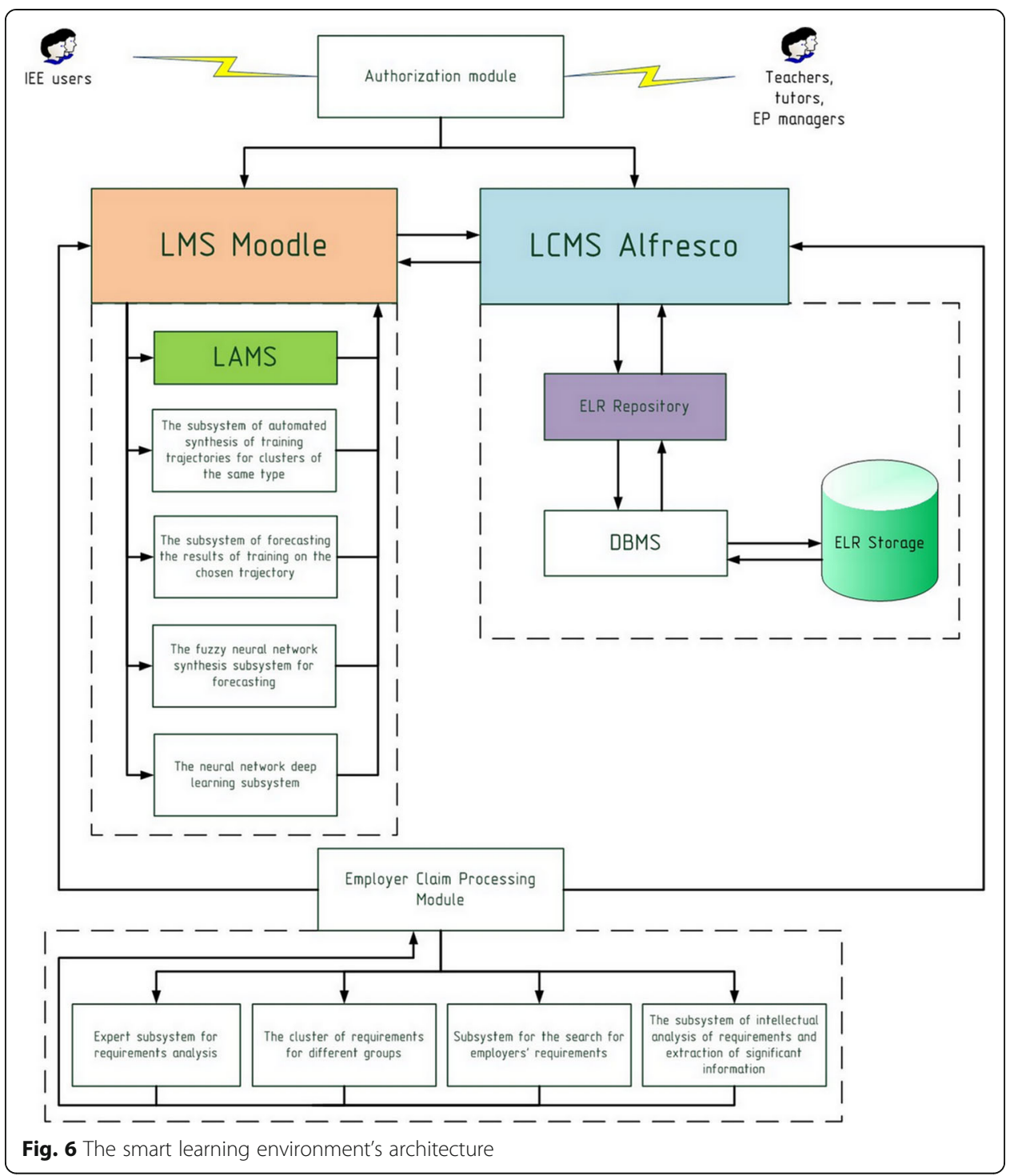

For the collection and intellectual analysis of requirements, open sources on the Internet are used, such as websites of employment agencies with a list of vacancies and specialist requirements, social networks, forums, etc. At the same time, polling technologies, questionnaires and search tools are used to adapt the individual learning trajectories and synthesize a personalized educational environment for the training of specialists. For questioning representatives of the real sector of the economy, an Internet site has also been created in the region for which the training specialist's process of the required profile is being implemented. For scanning and selection of job advertisements on the Internet, a search robot has been developed. It collects information about requirements for the specialist's competencies and forms the final report in XML format.

The main system's users are administrators, educational content authors (teachers, tutors), web designers, trainees, guests, employers. Access to the environment is provided through the Internet and local networks with support for mobile access technology. Administrators have the rights to any actions with content. They perform 
the managing functions of layout designer's work, assigning tasks, forming training modules and exporting resources to the storage. For each module, metadata is created with links to the resource and source objects. This allows to automate the training modules updating in the event that the author makes changes. Imposers have access to the materials assigned to them for work. Authors have the right to manage their materials and view the finished resources of other authors. All users can communicate through messaging systems.

\section{Conclusion}

The article presents a smart learning environment's model for the convergent education concept. Synthesis of electronic educational resources is realized on the Alfresco system, which is integrated with the Moodle learning management system and the learning activity management system. Intellectual mechanisms for managing personalized learning in the educational environment have been developed. The learning model in the smart environment is the convergent education model, which determines the possibility of using universal educational content for training in a variety of areas and specialties. The managing learning process in a smart environment is based on a lifecycles synchronization's model of educational programs, educational content and training specialist's levels. To manage the environment component lifecycles, a software-tool complex is developed that synchronizes the educational content with training programs, the employer's requirements and the training specialist's levels. The architecture integrates several software products and allows:

1. Use tools and built-in services that enhance the capabilities of the system.

2. Automate the synthesis and modernization of educational resources in accordance with the educational standards and employer's requirements.

3. Automate the synthesis of personalized learning paths with the educational content's selection to gain competencies.

4. Synthesize and train the predictive model of training specialists in the trajectories of training

5. Implement the training trajectory with an the assessment quality of specialist's training, the forecast models correction, the replacement or supplementation of educational resources

6. Update the educational content in accordance with the standards and employer's requirements

The architecture has made it possible to significantly reduce the costs of creating and maintaining its components lifecycles, to accelerate and simplify the educational content synthesis, and to realize its actualization mechanism. The environment is intended for use in colleges and universities, as well as in organizations for retraining and improving the training specialist's quality. It should be noted that this environment is not an alternative to open learning environments for users to use the existing search engines and online resources available on the Internet. In fact, it is an integrator for educational programs, technologies, tools and e-learning resources developed at a university, with the possibility of accessing to an alternative resources on the Internet, to realize the target learning process for convergent education. The main principle is 
openness to the external educational Internet space. Students and teachers use all available resources for both training in the proposed programs and for self-education. However, there are specific features for training specialists in each country and region, which are related to economic, social and cultural differences. To take into account these features, as well as the requirements of employers in a particular region, it is necessary to configure the components of the environment, which is performed using the proposed synchronization mechanism. Thus, the environment is a complex educational resource with an intelligent adaptive mechanism for setting individual educational trajectories, taking into account the requirements of educational programs, state standards and employers' requirements.

The smart learning environment for convergent education has now been implemented and is being used at the Penza State University (Russia, Penza) to manage the educational process and train specialists in accordance with the requirements of federal educational standards and employers' requirements in the Volga region of the Russian Federation. The environment has significantly reduced the time of synthesis and modernization of electronic educational content. In the further research, new intellectual mechanisms are being developed to synchronize and interact the educational environment components lifecycles on the basis of machine learning technologies.

Funding

The reported study was funded by RFBR according to the projects: № 18-010-00204, 16-07-00031, 17-30750010, 18-07-00975.

Authors' contributions

All coauthors contributed significantly to the research and this paper, and the lead author is the main contributor. All authors read and approved the final manuscript.

Ethics approval and consent to participate

Not applicable.

Competing interests

The authors declare that they have no competing interests.

\section{Publisher's Note}

Springer Nature remains neutral with regard to jurisdictional claims in published maps and institutional affiliations.

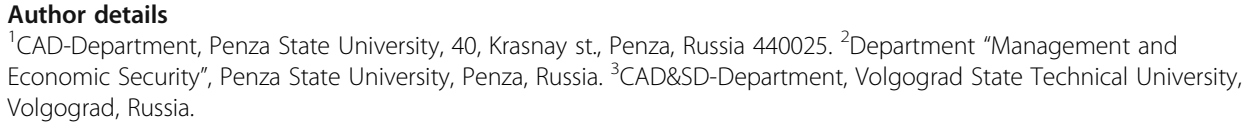

Received: 14 March 2018 Accepted: 25 July 2018

Published online: 13 August 2018

\section{References}

Alfresco website (2014). Retrieved from http://www.alfresco.com/ (Accessed 30 June 2018).

W Bainbridge, M Roco, Managing Nano-Bio-Info-Cognolnnovations: Converging Technologies in Society (Springer, NY, 2005)

J Bersin, in The Blended Learning Book: Best Practices, Proven Methodologies, and Lessons Learned. How Did We Get Here? The History of Blended Learning (John Wiley \& Sons, NY, 2004)

G Bhatia, M Anand, P Shrivastava, Cloud computing technology in education system. Int. J. Adv. Technol. Eng. Res. 2, 2250-3536 (2012)

J Canton, Designing the future: NBIC technologies and human performance enhancement. Ann. N. Y. Acad. Sci. 1013, 186-198 (2004)

T Chan, C Hue, C Chou, O Tzeng, Four spaces of network learning models. Comput. Educ. 37, 141-161 (2001)

$\mathrm{L}$ Chul, P Gunno, The impact of convergence between science and technology on innovation. J. Technol. Transf. $2,1-23(2016)$

E Cloete, Electronic education system model. Comput. Educ. 36, 171-182 (2001)

M Cooch, Moodle 2.0 First Look. (Packt Publishing Ltd, Birmingham, UK, 2010). 272p. 
MV Deev, TV Glotova, IG Krevskiy, in Proceedings of the 11th Joint Conference Knowledge-Based Software Engineering. Models of supporting continuing education of specialists for high-tech sector, vol 466 (Springer, Volgograd, 2014), pp. 100-112

MV Deev, TV Glotova, IG Krevskiy, Individualized Learning Trajectories Using Distance Education Technologies, Creativity in Intelligent, Technologies and Data Science. Series "Communications in Computer and Information Science", vol 535 (2015), pp. 778-792

J Duncan-Howell, K Lee, M-learning: Finding a place for mobile technologies within tertiary educational settings, in ICT Proceedings ascilite: Providing choices for learners and learning (Singapore, 2007) Retrieved from http://www.ascilite. org.au/conferences/singapore07/procs/duncan-howell.pdf (Accessed 25 June 2018).

AG Finogeev, LR Fionova, AA Finogeev, TQ Vinh, Learning Management System for the Development of Professional Competencies, Creativity in Intelligent Technologies and Data Science. Series «Communications in Computer and Information Science», vol 535 (2015), pp. 793-803

AG Finogeev, DS Parygin, AA Finogeev, The convergence computing model for big sensor data mining and knowledge discovery. HCIS 7, 11 (2017)

F Hamidi, Information Technology in Education. Procedia Computer Science 3, 369-375 (2011)

M Harmelen, Design trajectories: Four experiments in PLE implementation. Interact. Learn. Environ. 16(1), 35-46 (2008)

L Hirner, T Kochtanek, Quality indicators of online programs. Community College J. Res. Pract. 36(2), 122-130 (2012)

W Horton, Designing Web-Based Training: How to Teach Anyone Anything Anywhere Anytime (John Wiley \& Sons, NY, 2000)

G-J Hwang, in Proceedings of the Sensor Networks, Ubiquitous, and Trustworthy Computing. Criteria and strategies of ubiquitous learning (IEEE International Conference, 2006), pp. 72-77

AG Kravets, AG Belov, NP Sadovnikova, Models and methods of professional competence level research. Recent Patents on Computer Science. 9(2), 150-159 (2016)

LAMS Internationalization website (2012). Retrieved from https://lamscommunity.org/ (Accessed 15 July 2018).

Miller R. (2000). 'A brief introduction to holistic education', the encyclopaedia of informal education. Retrieved from http://infed.org/mobi/a-brief-introduction-to-holistic-education (Accessed 30 June 2018).

NMC Horizon Report (2017) Higher Education Edition. Retrieved from http://cdn.nmc.org/media/2017-nmchorizonreport-he-EN.pdf (Accessed 20 July 2018).

AD Olofsson, JO Lindberg, TE Hauge, Blogs and the design of reflective peer-to-peer technology-enhanced learning and formative assessment. Campus-Wide Information Systems 28, 183-194 (2011)

Personal Learning Environment. (2008). Retrieved from http://en.wikipedia.org/wiki/Personal_Learning_Environmnent (Accessed 23 July 2018).

M Roco, W Bainbridge, Converging Technologies for Improving Human Performance: Nanotechnology, Biotechnology, Information Technology and Cognitive Science (Arlington, 2004) Retrieved from http://www.wtec.org/ ConvergingTechnologies/Report/NBIC_report.pdf (Accessed 14 July 2018).

D Schatsky, C Muraskin, R Gurumurthy, Cognitive technologies: The real opportunities for business. Deloitte Review. $16,56-74$ (2015)

C Severance, A Whyte, The coming functionality mash-up in personal learning environments. Interact. Learn. Environ. 16(1), 47-62 (2008)

T Van Gog, D Sluijsmans, B Joosten, F Prins, Formative assessment in an online learning environment to support flexible on-the-job learning in complex professional domains. Educ. Technol. Res. Dev. 58(3), 311-324 (2010)

\section{Submit your manuscript to a SpringerOpen ${ }^{\circ}$ journal and benefit from:}

- Convenient online submission

- Rigorous peer review

- Open access: articles freely available online

High visibility within the field

- Retaining the copyright to your article

Submit your next manuscript at $\boldsymbol{\nabla}$ springeropen.com 